\title{
Light-harvesting chlorophyll a/b-binding protein-coding genes in jatropha and the comparison with castor, cassava and arabidopsis
}

\author{
Yongguo Zhao ${ }^{1,2}$, Hua Kong ${ }^{2}$, Yunling Guo ${ }^{2}$, Zhi Zou ${ }^{\text {Corresp. } 2}$ \\ ${ }^{1}$ Guangdong University of Petrochemical Technology, Maoming, China \\ 2 Key Laboratory of Biology and Genetic Resources of Tropical Crops, Ministry of Agriculture and Rural Affairs, Hainan Key Laboratory for Biosafety \\ Monitoring and Molecular Breeding in Off-Season Reproduction Regions, Institute of Tropical Biosciences and Biotechnology, Chinese Academy of Tropical \\ Agricultural Science, Haikou, China \\ Corresponding Author: Zhi Zou \\ Email address: zouzhi@itbb.org.cn
}

The Lhc (light-harvesting chlorophyll a/b-binding protein) superfamily represents a class of antennae proteins that play indispensable roles in capture of solar energy as well as photoprotection under stress conditions. Despite their importance, little information has been available beyond model plants. In this study, we presents a first genome-wide analysis of Lhc superfamily genes in jatropha (Jatropha curcas L., Euphorbiaceae), an oilbearing plant for biodiesel purpose. A total of 27 members were identified from the jatropha genome, which were shown to distribute over nine out of the 11 chromosomes. The superfamily number is comparable to 28 present in castor (Ricinus communis, Euphorbiaceae), but relatively less than 35 in cassava (Manihot esculenta, Euphorbiaceae) and 34 in arabidopsis (Arabidopsis thaliana) that experienced one or two recent wholegenome duplications (WGDs), respectively. In contrast to a high number of paralogs present in cassava and arabidopsis, few duplicates were found in jatropha as observed in castor, corresponding to no recent WGD occurred in these two species. Nevertheless, 26 orthologous groups representing four defined families were found in jatropha, and nearly one-to-one orthologous relationship was observed between jatropha and castor. By contrast, a novel group named SEP6 was shown to have been lost in arabidopsis. Global transcriptome profiling revealed a predominant expression pattern of most JcLhc superfamily genes in green tissues, reflecting their key roles in photosynthesis. Moreover, their expression profiles upon hormones, drought, and salt stresses were also investigated. These findings not only improve our knowledge on species-specific evolution of the Lhc supergene family, but also provide valuable information for further studies in jatropha. 
1 TITLE:

\section{Light-harvesting chlorophyll a/b-binding protein-coding genes in jatropha}

\section{3 and the comparison with castor, cassava and arabidopsis}

4

5

6 AUTHORS:

7 Yongguo Zhao ${ }^{1,2}$, Hua Kong², Yunling $\mathrm{Guo}^{2}$, Zhi Zou ${ }^{2, *}$

\section{E-MAIL ADDRESSES:}

zhaoyongguo@gdupt.edu.cn (Y.G Zhao), konghua@itbb.org.cn (H. Kong), guoyunling@itbb.org.cn (Y.L. Guo), zouzhi2008@126.com or zouzhi@itbb.org.cn(Z.Zou)

13

14

15

${ }^{1}$ Guangdong University of Petrochemical Technology, Maoming, Guangdong, China

${ }^{2}$ Hainan Key Laboratory for Biosafety Monitoring and Molecular Breeding in Off-Season Reproduction

Regions, Key Laboratory of Biology and Genetic Resources of Tropical Crops, Ministry of Agriculture and

Rural Affairs, Institute of Tropical Biosciences and Biotechnology, Chinese Academy of Tropical Agricultural Sciences, Haikou, Hainan, China

21

22

23

*To whom correspondence should be addressed. E-mail: zouzhi2008@126.com or zouzhi@itbb.org.cn.

ORCID ID: 0000-0003-2881-1932 


\section{RUNNING TITLE:}

28 Lhc superfamily genes in jatropha

\section{ABSTRACT}

30 The Lhc (light-harvesting chlorophyll a/b-binding protein) superfamily represents a class of antennae proteins 31 that play indispensable roles in capture of solar energy as well as photoprotection under stress conditions.

32 Despite their importance, little information has been available beyond model plants. In this study, we presents 33 a first genome-wide analysis of Lhc superfamily genes in jatropha (Jatropha curcas L., Euphorbiaceae), an oil34 bearing plant for biodiesel purpose. A total of 27 members were identified from the jatropha genome, which 35 were shown to distribute over nine out of the 11 chromosomes. The superfamily number is comparable to 28 present in castor (Ricinus communis, Euphorbiaceae), but relatively less than 35 in cassava (Manihot esculenta, Euphorbiaceae) and 34 in arabidopsis (Arabidopsis thaliana) that experienced one or two recent wholegenome duplications (WGDs), respectively. In contrast to a high number of paralogs present in cassava and arabidopsis, few duplicates were found in jatropha as observed in castor, corresponding to no recent WGD occurred in these two species. Nevertheless, 26 orthologous groups representing four defined families were found in jatropha, and nearly one-to-one orthologous relationship was observed between jatropha and castor. By contrast, a novel group named SEP6 was shown to have been lost in arabidopsis. Global transcriptome profiling revealed a predominant expression pattern of most $J c L h c$ superfamily genes in green tissues, reflecting their key roles in photosynthesis. Moreover, their expression profiles upon hormones, drought, and salt stresses were also investigated. These findings not only improve our knowledge on species-specific evolution of the $L h c$ supergene family, but also provide valuable information for further studies in jatropha.

47 Keywords: Jatropha curcas, Ricinus communis, Manihot esculenta, Arabidopsis thaliana, Light-harvesting chlorophyll a/b-binding protein, Lhc superfamily, Evolution, Synteny analysis, Whole-genome duplication, Expression profile

\section{INTRODUCTION}

51 Light-harvesting chlorophyll a/b-binding protein (Lhc) superfamily, defined by the presence of a conserved 
54 subunit S), and FCII (ferrochelatase II) (Klimmek et al., 2006; Zou \& Yang, 2019a). In contrast to an orphan 55 group present in both PsbS and FCII families, the Lhc family, initially known as CAB (chlorophyll a/b-binding 56 protein), contains two evolutionary groups named Lhca and Lhcb that are associated with photosystem I or II 57 (PSI/II), respectively (Jansson, 1999; Klimmek et al., 2006). The Lil family includes four diverse subfamilies, 58 i.e. OHP (one-helix protein), SEP (stress-enhanced protein), Lill or ELIP (early light-induced protein), and 59 Li18 or Psb33 (photosystem II protein 33) (Engelken et al., 2010; Zou, 2018). Among them, OHP and SEP can 60 be further divided into several groups: the OHP subfamily includes two groups named OHP1/Lil2 and 61 OHP2/Li16, whereas the SEP subfamily contains six groups, i.e. SEP1/Lil4, SEP2/Li15, SEP3/Lil3, SEP4, 62 SEP5, and SEP6 (Engelken et al., 2010; Zou \& Yang, 2019a). Investigation of their origin suggested that OHP 63 is more primitive, which is more likely to result from the plastid-encoded HLIP (high light-induced protein) 64 via gene transfer after the primary endosymbiosis (Koziol et al., 2007; Engelken et al., 2010). In addition to 65 light harvesting and transport, growing evidence shows that $L h c$ superfamily members are also involved in 66 regulation and distribution of excitation energy between PSI and PSII, maintenance of thylakoid membrane 67 structure, photoprotection as well as response to various stresses (Pan et al., 2011; Fan et al., 2015; Fristedt et al., 2015; Hey et al., 2017; Myouga et al., 2018). Jatropha curcas L. $(2 n=22)$, commonly known as jatropha, physic nut, barbados nut, or purging nut, is a perennial large shrub or small tree (Mazumdar et al., 2018; Zou et al., 2016, 2018). Jatropha belongs to the Euphorbiaceae family, which also includes castor (also known as castor bean, Ricinus communis L.) and cassava (Manihot esculenta Crantz) and is characterized with high photosynthesis and high biomass (Zou et al., 73 2018; Zou \& Yang, 2019a, 2019b). As a potential non-edible energy crop, jatropha produces high level of 74 fossil fuel-like oil in its seeds, which can be easily processed into biodiesel (Fairless, 2007; Berchmans \& 75 Hirata, 2008; Kumar \& Sharma, 2008; Maghuly \& Laimer, 2013). Additionally, this species also has several 76 unique characteristics like easy propagation, rapid growth, and adaptation to semiarid and barren soil 77 environments (Montes \& Melchinger, 2016). Although originated from Mesoamerica, jatropha can now be widely found in many tropical and subtropical countries of Africa and Asia (Wu et al., 2015; Li et al., 2017).

79 Nevertheless, its commercial cultivation has failed mainly due to low productivity (Montes \& Melchinger, 
81 of genes involved in yield formation are prerequisites. In this study, we would like to present a first genome-

82 wide analysis of the $L h c$ supergene family in jatropha, including gene structures, chromosome (Chr) locations,

83 evolutionary relationships, sequence characteristics, global expression profiles as well as comprehensive

84 comparison with arabidopsis, cassava, and castor. These results will not only improve our knowledge on

85 species-specific evolution of the Lhc supergene family, but also provide valuable information for further

86 functional analysis in jatropha.

\section{MATERIALS \& METHODS}

\section{Identification of $L h c$ superfamily genes}

89 As shown in Supplementary Table S1, 34 AtLhc superfamily genes were retrieved from TAIR

90 (https://www.arabidopsis.org/, Araport11) according to previous literatures. To facilitate evolutionary analysis,

9128 and 35 superfamily members present in castor and cassava (see Supplementary Table S1), two

92 Euphorbiaceous plants, were also obtained from Phytozome (Version 12,

93 https://phytozome.jgi.doe.gov/pz/portal.html). Homologs present in the jatropha genome (Wu et al., 2015)

94 were identified via the tBLASTn (Altschul et al., 1997; E-value, 1e-5) search by using above protein

95 sequences as queries. Gene models of candidates were revised via aligning mRNA to loci-encoding scaffolds.

96 Presence of the conserved CB domain (PF00504) was checked using MOTIF Search

97 (https://www.genome.jp/tools/motif/), and exon-intron structures were displayed using Gene Structure Display

98 Server (GSDS 2.0, https://gsds.cbi.pku.edu.cn/). Putative transmembrane helix (TMH) was predicted using

99 CCTOP (http://cctop.enzim.ttk.mta.hu/) as well as sequence alignment. Chloroplast transit peptide (TP) of

100 deduced proteins and biochemical parameters of mature peptides were determined using ChloroP (Version 1.1,

101 https://www.cbs.dtu.dk/services/ChloroP/) and ProtParam (https://web.expasy.org/protparam/), respectively.

\section{Chromosome location and synteny analysis}

103 Gene distribution on chromosomes was analyzed using MAPchart 2.3 (Voorrips, 2002). For synteny analysis,

104 the all-to-all BLASTP method was used to identify duplicate pairs, and MicroSyn (Cai et al., 2011) was used

105 to detect microsynteny. Orthologs across different species were inferred from the best-reciprocal-hit (BRH)-

106 based BLAST analysis as well as synteny analysis for jatropha and castor.

107 Sequence alignment, phylogenetic, and conserved motif analyses

Peer) reviewing PDF | (2019:08:40457:4:0:NEW 6 Dec 2019) 
108 Multiple sequence alignment was carried out using MUSCLE (Edgar, 2004). Phylogenetic tree construction

109 was performed using MEGA7 (Tamura et al., 2016) with the maximum likelihood method (bootstrap: 1,000).

110 Conserved motifs were identified using MEME (https://meme-suite.org/tools/meme): any number of

111 repetitions; maximum number of motifs, 25; minimum sites, 2; and, the optimum width of each motif, between

1126 and 100 residues.

\section{Gene expression analysis}

114 Transcriptome datasets used for expression profiling are shown in Supplementary Table S2. Except for

115 tissue-specific transcriptomes, other samples were performed for at least two biological replicates. Quality 116 control of raw reads was carried out using fastQC (https://www.

117 bioinformatics.babraham.ac.uk/projects/fastqc/). Read mapping were performed using Bowtie 2 (Langmead \&

118 Salzberg, 2012), and the relative transcript level of each gene was presented as FPKM (fragments per kilobase

119 of exon per million fragments mapped, for pair-ended samples) or RPKM (Reads per kilobase per million

120 mapped reads, for single-ended samples) (Mortazavi et al., 2008). RSEM (v1.2.27) (Li \& Dewey, 2011) with

121 parameters " $\log 2$ Ratio $\geq 1$ " and "FDR $<0.001$ " were used to determine differentially expressed genes.

\section{RESULTS}

\section{Identification and chromosome locations of 27 Lhc superfamily genes in jatropha}

124 The BLAST search resulted in 27 JcLhc superfamily genes from the jatropha genome (Wu et al., 2015), which 125 represent four previously defined families (i.e. $L h c, L i l, P s b S$, and FCII) or eight subfamilies (i.e. $L h c a, L h c b$, $126 P s b S, O H P, S E P, E L I P, P s b 33$, and $F C I I)$. Each subfamily contains one to nine members that were named 127 after their orthologs in castor (see below), i.e. JcLhca1-6, JcLhcb1.1-1.2, JcLhcb2-8, JcPsbS, JcELIP,

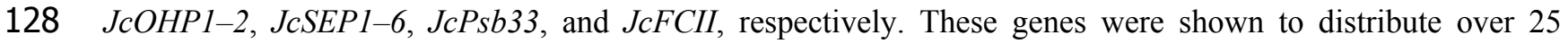
129 scaffolds. Although most scaffolds contain a single member, two of them harbor two, i.e. scaffold160 (i.e. $130 J$ JLhcb1.1 and JcLhcb1.2) and scaffold211 (i.e. JcLhca6 and JcSEP5) (Table 1). With the help of 1,208 131 available genetic markers, these genes were further anchored to nine chromosomes, and the gene number of 132 each chromosome varies from one to five (Fig. 1).

133 The expression of all JcLhc genes was supported by available Sanger sequencing-derived expressed 134 sequence tags (ESTs) and/or RNA sequencing (RNA-seq), where $J c L h c b 1.1$ harbors the maximum of 28 EST 
135 hits. The intron number of these genes varies from zero to nine: approximately $11.11 \%$ of genes are intronless, 136 and $29.63 \%, 22.22 \%, 11.11 \%, 11.11 \%, 11.11 \%$ or $3.70 \%$ contain two, one, three, four, five and nine introns,

137 respectively (Table 1 and Fig. 2). Similar exon-intron structure was also observed in castor, cassava, and 138 arabidopsis (see Supplementary Table S1), implying a conserved evolution between these species. The 139 average length of coding sequences (CDS) is about $760 \mathrm{bp}$, varying from $357 \mathrm{bp}$ of $J c O H P 1$ to $1,500 \mathrm{bp}$ of $140 J c F C I I$. Compared with CDS, the intron length is relatively more variable, ranging from 79 bp of $J c L h c b 6$ to 1418,100 bp of $J c F C I I$ and with the average length of 1,259 bp (Table 1 and Fig. 2). The CDS of JcLhcb1.1 and $142 J c L h c b 1.2$, which are reversely clustered on scaffold160, was shown to exhibit $96.7 \%$ identity. Thereby, they 143 are more likely to result from tandem duplication (Zou et al., 2019; Zou \& Yang, 2019a, 2019c).

\section{Synteny analysis and determination of orthologous groups}

145 Orthologs of $J c L h c$ superfamily genes in castor, cassava, and arabidopsis were further identified by using the 146 BRH method, resulting in 26 orthologous groups (OGs) when the definition was confined to at least one 147 member present in more than two species examined (Table 1). The result is highly consistent with

148 phylogenetic analysis (see below) as well as synteny analysis performed between jatropha and castor, where 149 one-to-one orthologous relationship was observed with exception of the Lhcb1 group with two-to-three (Table 150 1). Interestingly, RcLhcb1.2, which may originate by dispersed duplication, is located on scaffold 30005 151 together with RcLhca3. However, no collinear gene was found for RcLhcb1.2 in jatropha (see Supplementary 152 Fig. S1). By contrast, orthologous relationships between jatropha and cassava/arabidopsis are relatively 153 complex, which include one-to-one, one-to-two, one-to-three, and two-to-five, corresponding to one or more 154 recent WGDs occurred in these two species. It is worth noting that, SEP6, a recently identified group that is 155 present in jatropha, castor, and cassava, is absent from arabidopsis (Table 1), implying species/lineage-specific 156 gene loss. Additionally, species-specific gene expansion was also observed: duplicates identified in jatropha 157 (one) and castor (two) were shown to result from tandem or dispersed duplication, respectively; nine duplicates 158 identified in cassava were derived from tandem duplication (three) and whole-genome duplication (WGD) 159 (six); in arabidopsis, four or five duplicates were derived from tandem duplication and WGD, respectively 160 (Table 1 and Supplementary Table S1). 
161 Although not exactly the same within a family, the exon-intron structure is highly conserved within a certain

162 OG: Lhcb1 and SEP4 are intronless; one-intron-containing groups include Lhcb2/-4/-6/-8, OHP2, and SEP2,

163 whereas two-intron groups include Lhca3/-4, Lhcb3, ELIP, OHP1, SEP3/-6, and Psb33; Lhca1 and SEP1

164 feature three introns, whereas Lhca2/-6, and SEP5 feature four introns; three groups (i.e. Lhcb5/-7 and Lhca5)

165 contain five introns, whereas only one group (i.e. FCII) harbors nine introns (Fig. 2, Table 1, and

166 Supplementary Table S1).

167 Phylogenetic analysis, sequence features, and conserved motifs

168 As shown in Table 1, the deduced JcLhc superfamily proteins consist of 118-499 amino acids (AA) with one

169 to four TMHs (Supplementary Fig. S2), and the predicted length of transit peptide ranges from 31 to 100

170 residues (Table 1). Several physical and chemical parameters of mature peptides were further calculated: the

171 molecular weight (MW) and isoelectric point $(p \mathrm{I})$ values of mature proteins in jatropha range from 7.55 to

17246.76 kilodalton $(\mathrm{kDa})$ or from 4.56 to 9.99 , respectively; about $81.48 \%$ of JcLhc superfamily proteins harbor

173 a $p$ I value of less than 7 , which is relatively less than $85.71 \%$ in castor, $91.43 \%$ in cassava, or $91.18 \%$ in

174 arabidopsis; and, about $59.26 \%$ of JcLhc superfamily proteins harbor a grand average of hydropathicity

175 (GRAVY) value of less than 0 , which is relatively less than $64.29 \%$ in castor, $62.86 \%$ in cassava, or $73.53 \%$ in

176 arabidopsis (Table 1 and Supplementary Table S1).

177 Except for JcPsb33 that contains a CB-like domain (see Supplementary Fig. S3), all other JcLhc 178 superfamily proteins include the core CB domain of approximately 20 AA (see Supplementary Table S1).

179 Nevertheless, their overall sequence similarity was shown to be considerably low, even within the conserved

180 Lhc family (ranging from $27.2 \%$ to $98.5 \%$, see Supplementary Table S3). To keep the analysis reliable, an

181 independent phylogenetic tree was constructed for each subfamily by using full-length proteins from jatropha,

182 castor, cassava, and arabidopsis. As shown in Fig. 3a, subfamilies Lhca, Lhcb, OHP, and SEP are clearly

183 clustered into six, eight, two or six phylogenetic groups respectively, corresponding to 22 OGs as described

184 above, i.e. Lhca1-6, Lhcb1-8, OHP1, OHP2, and SEP1-6. Among them, Lhcb8 and SEP6 exhibit a closer

185 relationship with Lhcb4 and SEP3, with a similarity of 79.5\% or 55.5\%, respectively (Supplementary Table

186 S3), where JcLhcb8 harbors a relative shorter C-terminal in relation to JcLhcb4 (Supplementary Fig. S2).

Peer) reviewing PDF | (2019:08:40457:4:0:NEW 6 Dec 2019) 
To reveal possible divergence of members within a certain OG and between different OGs/(sub)families, conserved motifs were analyzed using MEME. As shown in Fig. 3b and Table 2, motifs are highly variable between subfamilies or even between different evolutionary groups, and considerably more motifs were identified in the Lhc family as compared with PsbS, FCII, and Lil families. Among 25 motifs identified, Motif 1 , which is characterized as the CB domain, is widely distributed, including Psb33s. Motif 19, which is

192 characterized as chloroplast transit peptide, is also widely found. Motifs 25 and 11 are characterized as part of 193 the Rieske-like domain (PF13806), where Motif 11 is Psb33-specific and Motif 25 is also present in Lhca1s.

194 The Ferrochelatase domain (PF00762), which is FCII-specific, was shown to include Motifs 21, 12, 10, and 24. Among them, Motif 10 is also present in SEP3s and SEP6s. Motif 7, which includes the WYGPDR/WYGEER domain, is widely found in Lhcb1, $-2,-3,-5$, and -7 groups. WYGPDR has been proven to be essential for trimerization (Hobe et al., 1995; Rogl \& Kühlbrandt, 1999), however, experimental evidence is still needed for WYGPD and WYGEER varieties. By contrast, little information is available for other motifs, including several group-specific motifs such as Motifs 8, 9, 18, 20, and 22.

200 Although these motifs are usually conserved within a certain OG, species-specific gain or loss was also 201 observed. For example, the conserved Motifs 15, 23, and 10 are absent from AtLhca5, AtLhca3 or AtFCII, 202 respectively, whereas the widely present Motif 8 in SEP3s and SEP6s is replaced by Motif 3 in MeSEP6 (Fig. $2033)$.

\section{Expression profiles of JcLhc superfamily genes}

205 Global gene expression profiles were investigated in various tissues, i.e. root (from 15-day-old seedlings), 206 leafage (from 4-year-old plants, half expanded), leaf (mature leaf, fully expanded), IND (undifferentiated 207 inflorescence of $0.5 \mathrm{~cm}$ diameter), PID1 (female flower with carpel primordia beginning to differentiate), PID2 208 (female flower with three distinct carpels formed), STD1 (male flower with stamen primordia beginning to 209 differentiate), STD2 (male flower with ten complete stamens formed), and developing seed (19-28 days after 210 pollination). Despite the expression of all identified genes, their transcript levels are highly variable over

211 different tissues. As shown in Fig. 4, the majority of $J c L h c$ superfamily genes are predominantly expressed in 212 leaf, and the total transcript level of the whole superfamily in STD1, PID2, STD2, PID1, leafage, root, and 213 seed accounts for $42.82 \%, 24.26 \%, 23.71 \%, 21.41 \%, 21.16 \%, 18.01 \%, 5.83 \%$, or $1.75 \%$ of that in leaf, 
214 respectively. According to tissue-specific expression patterns, JcLhc superfamily genes can be divided into

215 five main clusters: Cluster I is mostly expressed in leafage, including $J c P s b S, J c F C I I$, and four Lils (i.e. $216 J_{c O H P 2}, J_{C S E P} 1, J_{C S E P}$, and $J_{C E L I P)}$; Clusters II and III that contain the vast majority of $L h c$ family 217 members and include approximately $63.00 \%$ of the whole superfamily are predominantly expressed in mature 218 leaf, where Cluster III is also highly abundant in leafage (i.e. JcLhca6, JcLhcb7, JcLhcb8, JcOHP1, JcSEP3,

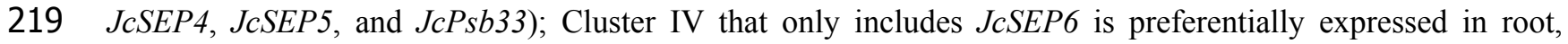
220 whereas Cluster V is typically expressed in STD1 (i.e. JcLhcb1.2, JcLhcb2, and JcLhcb6) (Fig. 4). It is worth 221 noting that, JcLhcb1.1 represents the most expressed gene in most tissues examined, implying its key roles.

222 Given drought and salt are two of the most important abiotic stresses affecting plant growth and 223 development, photosynthesis, and crop yield, we thereby investigated the response patterns of $J c L h c$ 224 superfamily genes post drought or salt treatment in leaves and roots of eight-week-old seedlings. After 225 withholding irrigation for 1,4 or $7 \mathrm{~d}$, the total superfamily transcripts in roots were not significantly changed, 226 by contrast, initial increase followed by significant decrease were observed in leaves. The result is consistent 227 with the fact that the net photosynthesis rate $(\mathrm{Pn})$ and stomatal conductance had decreased to $80 \%$ or $20 \%$ of 228 those in the control after the start of the stress treatment for 2 and $7 \mathrm{~d}$, respectively (Zhang et al., 2015). For 1 $\mathrm{d}$, seven or three genes were significantly regulated in leaves and roots, respectively. Among them, JcLhcb1.1,

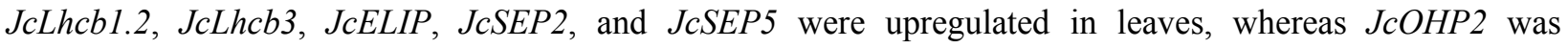
downregulated; $J c L h c b 3$ and $J c F C I I$ were downregulated in roots, whereas $J c P s b S$ was upregulated. For $4 \mathrm{~d}$, ten or seven genes were significantly regulated in leaves and roots, respectively. Among them, JcLhca4,

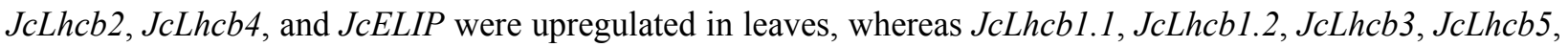
$J c L h c b 7$, and JcLhcb8 were downregulated; JcLhca3, JcLhca4, JcLhcb3, JcLhcb8, and JcPsbS were upregulated in roots, whereas $J_{c L h c a l}$ and $J c F C I I$ were downregulated. For 7 d, 19 or seven genes were significantly regulated in leaves and roots, respectively. Among them, JcLhca4, JcLhcb2, JcPsbS, JcELIP, JcOHP1, JcSEP2, and JcSEP5 were upregulated in leaves, whereas JcLhca3, JcLhca5, JcLhcb1.1, JcLhcb1.2, JcLhcb3, JcLhcb5, JcLhcb6, JcLhcb8, JcSEP1, JcSEP3, JcSEP4, and JcPsb33 were downregulated; JcLhca1, upregulated (Fig. 5). 
241 Similar to drought treatment, after applying $100 \mathrm{mM} \mathrm{NaCl}$ for $2 \mathrm{~h}, 2 \mathrm{~d}$ or $7 \mathrm{~d}$, gradual downregulation of

242 total transcripts was only observed in leaves. For $2 \mathrm{~h}$, five or three genes were significantly regulated in leaves 243 and roots, respectively. Among them, $J_{c L h c b 2}, J_{c} O H P 2, J_{c S E P}$, and $J c F C I I$ were downregulated in leaves, 244 whereas $J c L h c b 1.2$ was upregulated; in roots, $J c L h c b 8, J c S E P 5$, and $J c F C I I$ were downregulated. For $2 \mathrm{~d}$, six 245 genes were significantly regulated in both leaves and roots, respectively. Among them, JcELIP, JcSEP2, $246 J C S E P 4$, and $J_{c F C I I}$ were upregulated in leaves, whereas $J_{c} O H P 2$ and $J c S E P 1$ were downregulated; JcLhcal, $247 J_{c L h c a 2}, J c L h c b 8$, and JcSEP5 were upregulated in roots, whereas JcLhcb1.1 and JcLhcb1.2 were 248 downregulated. For $7 \mathrm{~d}$, nine or seven genes were significantly regulated in both leaves and roots, respectively. 249 Among them, JcLhca3, JcLhcb1.1, JcLhcb1.2, JcLhcb3, JcLhcb5, JcLhcb8, JcSEP1, and JcSEP4 were 250 downregulated in leaves, whereas $J c L h c b 2$ was upregulated; JcLhca3, JcLhcb1.2, JcLhcb3, JcLhcb5, and $251 J C S E P 5$ were downregulated in roots, whereas $J_{C E L I P}$ and $J c F C I I$ were upregulated (Fig. 5). Downregulation

252 of most regulated genes is highly consistent with gradual decrease of Pn, where the Pn values of 2 and $7 \mathrm{~d}$ after 253 stress treatment accounted for $83 \%$ or $50 \%$ of the control, respectively (Zhang et al., 2014).

254 Responses to gibberellin acid (GA) and 6-benzylaminopurine (BA) treatments were also examined in young 255 axillary buds. Application of $10 \mu \mathrm{M}$ GA for $12 \mathrm{~h}$ resulted in one upregulated (i.e. JcFCII) and two downregulated (i.e. $J C S E P 2$ and $J C S E P 5)$ genes, in contrast, no evident effect was observed for the same concentration of BA (Fig. 5).

\section{DISCUSSION}

259 In green plants, the Lhc superfamily is consisted of four antennae protein families that play essential roles in 260 light-harvesting and photoprotection (Jansson, 1999; Klimmek et al., 2006; Zou, 2018). Despite their

261 importance, extensive research is still limited to the model plant arabidopsis and few other species such as 262 Chlamydomonas reinhardtii, Physcomitrella patens, castor, and cassava (Elrad \& Grossman, 2004; Klimmek 263 et al., 2006; Alboresi et al., 2008; Engelken et al., 2010; Zou et al., 2013; Zou \& Yang, 2019a). Among them, 264 it's well established that cassava and arabidopsis experienced one or two additional WGDs after the so-called $\gamma$ 265 hexaploidization event shared by all core eudicots: The recent WGD occurred in cassava is called $\rho$, which was 266 estimated to occur within a window of 39-47 million years ago (Mya) (Bredeson et al., 2016; Zou et al., 2019; 267 Zou \& Yang, 2019a, 2019b, 2019c), whereas two recent WGDs occurred in arabidopsis are known as $\beta$ and $\alpha$, 
268

269

270

271

272

273

274

275

276

277

278

279

280

281

282

283

284

285

286

287

288

289

290

291

292

293

294

which were estimated to occur within a window of 61-65 or 23-50 Mya, respectively (Bowers et al., 2003). From this point of view, analysis of species without recent WGDs may improve our knowledge on speciesspecific evolution of this special gene family. Jatropha, another economically Euphorbiaceous plant for potential biodiesel purpose, is a good candidate for such study. According to comparative genomics analysis, jatropha may share a common ancestor with cassava and castor at approximately 65 Mya (Bredeson et al., 2016), and no additional WGD occurred after their divergence.

In the present study, a first genome-wide identification and global analysis of $L h c$ superfamily genes were performed in jatropha, and the superfamily number of 27 members identified in this species is comparable to 28 reported in castor but relatively less than 35 or 34 present in cassava and arabidopsis, respectively (Klimmek et al., 2006; Engelken et al., 2010; Zou et al., 2013; Zou \& Yang, 2019a). Nevertheless, 26 OGs representing four families (i.e. Lhc, Lil, PsbS, and FCII) were found in jatropha as observed in castor and cassava (Zou et al., 2013; Zou \& Yang, 2019a). Few recent duplicates were identified in jatropha as well as castor, corresponding to no recent WGD occurred in these two species (Chan et al., 2010; Wu et al., 2015). Compared with castor that contains two dispersed duplicates, only one duplicate derived from tandem duplication was found in jatropha. By contrast, considerably more duplicates, i.e. nine, were identified in both cassava and arabidopsis (Supplementary Table S1), reflecting the occurrence of one or two recent WGDs (Bowers et al., 2003; Bredeson et al., 2016). Despite having the same number of duplicates, cassava contains relatively more WGD duplicates (6 vs 5) but less local duplicates (3 vs 4), implying species-specific evolution pattern. Interestingly, duplicates in both jatropha and castor are confined to the Lhcb1 group, however, in cassava and arabidopsis, local duplicates were also found in the Lhcb2 group (Supplementary Table S1).

Among four families identified, both PsbS and FCII include a single member in four species examined in this study. By contrast, Lhe and Lil families are relatively complex. The Lhc family contains 14 OGs representing two subfamilies (i.e. Lhca and Lhcb), whereas the Lil family includes ten OGs representing four subfamilies (i.e. ELIP, OHP, SEP, and Psb33). According to crystal analyses, the Lhc family members usually contain three alpha-helixes, whereas the PsbS family features four (Kühlbrandt et al., 1994; Pan et al., 2011; Fan et al., 2015). By contrast, one to three helixes were shown to be present in Lil proteins, i.e. one for OHPs and Psb33s, two for SEPs, and three for ELIPs (Jansson, 1999; Engelken et al., 2010; Fristedt et al., 2015; 
295 Beck et al., 2017). Similar results were also observed in this study, however, both JcSEP5 and JcFCII were 296 shown to contain a single helix.

297 It is noteworthy that, among 26 OGs identified, SEP6 is absent from arabidopsis. SEP6 exhibits about $29841.7 \%, 40.5 \%$ or $39.0-40.3 \%$ sequence identity with SEP3 in jatropha, castor and cassava respectively, 299 implying their early divergence and species-specific gene loss. Indeed, SEP6 orthologs were broadly found in 300 dicots, including Carica papaya and Aquilegia coerulea (Zou \& Yang, 2019a). Additionally, Lhcb8 shows 301 approximately $72.0 \%, 69.9 \%, 72.6 \%$ or $64.2-65.3 \%$ identity with Lhcb4 in jatropha, castor, cassava, and 302 arabidopsis, respectively. Lhcb8 is widely present in core eudicots but not in A. coerulea and monocots, 303 suggesting its recent origin. According to synteny analysis performed in arabidopsis, Lhcb8 is more likely to 304 be a duplicate of Lhcb4 generated along the $\gamma$ event (Bowers et al., 2003; Wang et al., 2013).

305 Potential roles of $J c L h c$ superfamily genes could be inferred from their expression patterns and function306 characterized orthologs in arabidopsis and other species. According to GO annotation, they belong to thylakoid 307 membrane proteins that have activity of chlorophyll binding, pigment binding, xanthophyll binding, lipid 308 binding, protein binding, iron-sulfur cluster binding, oxidoreductase, ferrochelatase as summarized in 309 Supplementary Table S4. Our transcriptional profiling not only supports the expression of all $27 J c L h c$ 310 superfamily genes identified in this study, but also reveals key genes in a certain tissue, development stage or 311 environment condition. Similar to that reported in arabidopsis (Jansson, 1999; Klimmek et al., 2006), genes encoding JcLhca1 to -4 and JcLhcb1 to -6 , which are characterized as abundant Lhc proteins, were highly expressed in most examined jatropha tissues, especially in mature leaf. By contrast, four genes encoding socalled rare Lhc proteins (i.e. JcLhca5, JcLhca6, JcLhcb7, and JcLhcb8) are lowly expressed, exhibiting a

315 similar expression pattern to members of Lil, PsbS, and FCII families. The result is consistent with our cluster 316 analysis, which divides $J c L h c$ superfamily genes into five clusters named I, II, III, IV, and V. These genes 317 encoding abundant Lhc proteins belong to Clusters II and V, whereas rare Lhc genes were divided into Cluster 318 III with the exception of JcLhca5. Clustering JcLhca5 into Cluster II is due to its leaf-preferential expression pattern, but not the transcript level. Compared with mature leaf, leafage is considerably more sensitive to high 
322 member in Clusters IV, is lowly expressed in most examined tissues with the exception of root. As a recently 323 identified superfamily member, the detailed function of SEP6 still needs to be investigated. Furthermore, most $324 J c L h c$ superfamily genes were regulated by drought and/or salt, two most important abiotic stresses affecting 325 crop growth and yield (Zhang et al., 2014, 2015). As expected, more genes are downregulated, especially for 326 the leaf tissue, corresponding to decrease of transpiration rate and stomatal conductance (Zhang et al., 2015).

327 Nevertheless, frequent upregulation of certain members was also observed, i.e. JcLhca4, JcELIP, JcPsbS, $328 J_{C S E P} 2, J_{C S E P 5}$, and $J_{C} O H P 1$. Interestingly, $J_{C L h c a}$ and $J_{c L h c a 5}$ exhibit distinct responses upon drought or 329 salt stress, whereas $J c L h c a 2$ was specifically regulated by salt and JcLhca4, JcLhcb4, JcLhcb6, JcLhcb7, $330 J c P s b S, J_{c} O H P 1, J_{c S E P} 2$ and $J_{c P s} 333$ were only regulated by drought. The involvement of $L h c$ superfamily 331 genes in stress response has been well documented in arabidopsis and other species, including high light, 332 chloroplast retrograde signal, oxidative stress, abscisic acid, etc. (Montané \& Kloppstech, 2000; Staneloni et 333 al., 2008; Gerotto et al., 2011; Tibiletti et al., 2016). For example, ELIPs, as the name suggests, are induced

334 by early and high light, as well as other stresses such as UV-B, cold, heat, drought, salt, hypoxia, and anoxia 335 described in this study and elsewhere (Heddad et al., 2006; Hayami et al., 2015). In arabidopsis, knockout and 336 overexpression of ELIPs resulted in decreased chlorophyll levels (Casazza et al., 2005; Tzvetkova-Chevolleau 337 et al., 2007). Another high-light induced gene, $P s b S$, acts as the main sensor of the low $\mathrm{pH}$ in plants and plays 338 an essential role in nonphotochemical quenching (Bergantino et al., 2003; Li et al., 2004; Gerotto et al., 2011; 339 Fan et al., 2015; Tibiletti et al., 2016). OHPs, which are related to HLIPs in cyanobacteria, are essential for the 340 formation of the PSII reaction center. In arabidopsis, mutations in AtOHP1 or AtOHP2 caused severe growth 341 deficits, reduced pigmentation, and disturbed thylakoid architecture (Beck et al., 2017; Hey and Grimm, 2018;

342 Myouga et al., 2018; Li et al., 2019). By contrast, two plant hormones (i.e. BA and GA), which can improve 343 shoot branching after application to young axillary buds ( $N i$ et al., 2017), had little effect on transcriptional 344 regulation of $J c L h c$ superfamily genes.

\section{CONCLUSION}

346 This study presents a first genomics analysis of the $L h c$ supergene family in jatropha, resulting in 27 members 347 that are distributed across nine out of 11 chromosomes. Despite a relatively smaller number of members, 26 348 orthologous groups representing four families were found, where SEP6 represents a novel group that has been 
349 lost in the model plant arabidopsis. Nearly one-to-one orthologous relationship was observed between jatropha

350 and castor, however, species-specific gene expansion was observed in these two species as well as cassava and

351 arabidopsis. Exon-intron structures, protein motifs, and expression profiles of $J c L h c$ superfamily genes were

352 also analyzed and discussed. These findings provide valuable information for further studies in jatropha and

353 species beyond.

\section{ACKNOWLEDGEMENTS}

355 The authors appreciate those contributors who make the related genome and transcriptome data accessible in

356 public databases. They also thank the editor and two reviewers for their helpful suggestions.

\section{ADDITIONAL INFORMATION AND DECLARATIONS}

\section{Funding}

359 This work was supported by the National Natural Science Foundation of China (31700580 and 31971688), the

360 Natural Science Foundation of Hainan province (319MS093), the Central Public-interest Scientific Institution

361 Basal Research Fund for Chinese Academy of Tropical Agricultural Sciences (1630022019017 and

362 1630052017011), and the Research Fund of Guangdong University of Petrochemical Technology (2018rc55).

363 The funders had no role in study design, data collection and analysis, decision to publish, or preparation of the

364 manuscript.

\section{Grant Disclosures}

366 The following grant information was disclosed by the authors:

367 National Natural Science Foundation of China: 31700580 and 31971688.

368 Natural Science Foundation of Hainan province: 319MS093.

369 Central Public-interest Scientific Institution Basal Research Fund for Chinese Academy of

370 Tropical Agricultural Sciences: 1630052017011 and 1630022019017.

371 Research Fund of Guangdong University of Petrochemical Technology: 2018rc55.

\section{Competing interests}

373 The authors declare there are no competing interests.

\section{Supplemental Information}

375 Supplemental information for this article can be found online at http://dx.doi.org/. 
376

377

378

379

380

381

382

383

384

385

386

387

388

389

390

391

392

393

394

395

396

397

398

399

400

401

402

403

404

405

406

407

408

409

410

\section{REFERENCES}

Alboresi A, Caffarri S, Nogue F, Bassi R, Morosinotto T. 2008. In silico and biochemical analysis of Physcomitrella patens photosynthetic antenna: identification of subunits which evolved upon land adaptation. PLoS One 3(4):e2033 DOI 10.1371/journal.pone.0002033.

Altschul SF, Madden TL, Schaffer AA, Zhang J, Zhang Z, Miller W, Lipman DJ. 1997. Gapped BLAST and PSI-BLAST: a new generation of protein database search programs. Nucleic Acids Research 25(17):3389-3402 DOI 10.1093/nar/25.17.3389.

Beck J, Lohscheider JN, Albert S, Andersson U, Mendgen KW, Rojas-Stütz MC, Adamska I, Funck D. 2017. Small one-helix proteins are essential for photosynthesis in Arabidopsis. Frontiers in Plant Science 8:7 DOI 10.3389/fpls.2017.00007.

Berchmans HJ, Hirata S. 2008. Biodiesel production from crude Jatropha curcas L. seed oil with a high content of free fatty acids. Bioresource Technology 99(6):1716-1721 DOI 10.1016/j.biortech.2007.03.051.

Bergantino E, Segalla A, Brunetta A, Teardo E, Rigoni F, Giacometti GM, Szabò I. 2003. Light- and pHdependent structural changes in the PsbS subunit of photosystem II. Proceedings of the National Academy of Sciences of the United States of America 100(25):15265-15270 DOI 10.1073/pnas.2533072100.

Bowers JE, Chapman BA, Rong J, Paterson AH. 2003. Unravelling angiosperm genome evolution by phylogenetic analysis of chromosomal duplication events. Nature 422(6930):433-438 DOI 10.1038/nature01521.

Bredeson JV, Lyons JB, Prochnik SE, Wu GA, Ha CM, Edsinger-Gonzales E, Grimwood J, Schmutz J, Rabbi IY, Egesi C, Nauluvula P, Lebot V, Ndunguru J, Mkamilo G, Bart RS, Setter TL, Gleadow RM, Kulakow P, Ferguson ME, Rounsley S, Rokhsar DS. 2016. Sequencing wild and cultivated cassava and related species reveals extensive interspecific hybridization and genetic diversity. Nature Biotechnology 34(5):562-70. DOI 10.1038/nbt.3535.

Cai B, Yang X, Tuskan GA, Cheng ZM. 2011. MicroSyn: a user friendly tool for detection of microsynteny in a gene family. BMC Bioinformatics 12:79 DOI 10.1186/1471-2105-12-79.

Casazza AP, Rossini S, Rosso MG, Soave C. 2005. Mutational and expression analysis of ELIP1 and ELIP2 in Arabidopsis thaliana. Plant Molecular Biology 58(1):41-51 DOI 10.1007/s11103-005-4090-1.

Chan AP, Crabtree J, Zhao Q, Lorenzi H, Orvis J, Puiu D, Melake-Berhan A, Jones KM, Redman J, Chen G, Cahoon EB, Gedil M, Stanke M, Haas BJ, Wortman JR, Fraser-Liggett CM, Ravel J, Rabinowicz PD. 2010. Draft genome sequence of the oilseed species Ricinus communis. Nature Biotechnology 28(9):951-956 DOI 10.1038/nbt.1674.

Edgar RC. 2004. MUSCLE: multiple sequence alignment with high accuracy and high throughput. Nucleic Acids Research 32:1792-1797 DOI 10.1093/nar/gkh340.

Engelken J, Brinkmann H, Adamska I. 2010. Taxonomic distribution and origins of the extended LHC (lightharvesting complex) antenna protein superfamily. BMC Evolution Biology 10:233 DOI 10.1186/1471-2148-10-

Peer] reviewing PDF | (2019:08:40457:4:0:NEW 6 Dec 2019) 
411

412

413

414

415

416

417

418

419

420

421

422

423

424

425

426

427

428

429

430

431

432

433

434

435

436

437

438

439

440

441

442

443

444

445

446

233.

EIrad D, Grossman AR. 2004. A genome's-eye view of the light-harvesting polypeptides of Chlamydomonas reinhardtii. Current Genetics 45(2):61-75 DOI 10.1007/s00294-003-0460-x.

Fairless D. 2007. Biofuel: the little shrub that could--maybe. Nature 449(7163):652-655 DOI 10.1038/449652a.

Fan M, Li M, Liu Z, Cao P, Pan X, Zhang H, Zhao X, Zhang J, Chang W. 2015. Crystal structures of the PsbS protein essential for photoprotection in plants. Nature Structural \& Molecular Biology 22(9):729-735 DOI 10.1038/nsmb.3068.

Fristedt R, Herdean A, Blaby-Haas CE, Mamedov F, Merchant SS, Last RL, Lundin B. 2015. PHOTOSYSTEM II PROTEIN33, a protein conserved in the plastid lineage, is associated with the chloroplast thylakoid membrane and provides stability to photosystem II supercomplexes in Arabidopsis. Plant Physiology 167(2):481-492 DOI 10.1104/pp.114.253336.

Gerotto C, Alboresi A, Giacometti GM, Bassi R, Morosinotto T. 2011. Role of PSBS and LHCSR in Physcomitrella patens acclimation to high light and low temperature. Plant Cell \& Environment 34:922-932 DOI 10.1111/j.1365-3040.2011.02294.x.

Heddad M, Norén H, Reiser V, Dunaeva M, Andersson B, Adamska I. 2006. Differential expression and localization of early light-induced proteins in Arabidopsis. Plant Physiology 142(1):75-87 DOI 10.1104/pp.106.081489.

Hayami N, Sakai Y, Kimura M, Saito T, Tokizawa M, Iuchi S, Kurihara Y, Matsui M, Nomoto M, Tada Y, Yamamoto YY. 2015. The responses of Arabidopsis early light-induced protein2 to ultraviolet B, high light, and cold stress are regulated by a transcriptional regulatory unit composed of two elements. Plant Physiology 169(1):840-855 DOI 10.1104/pp.15.00398.

Hey D, Grimm B. 2018. Requirement of ONE-HELIX PROTEIN 1 (OHP1) in early Arabidopsis seedling development and under high light intensity. Plant Signaling \& Behavior 29:1-3 DOI 10.1080/15592324.2018.1550317.

Hey D, Rothbart M, Herbst J, Wang P, Müller J, Wittmann D, Gruhl K, Grimm B. 2017. LIL3, a lightharvesting complex protein, links terpenoid and tetrapyrrole biosynthesis in Arabidopsis thaliana. Plant Physiology 174(2):1037-1050 DOI 10.1104/pp.17.00505.

Hobe S, Förster R, Klingler J, Paulsen H. 1995. N-proximal sequence motif in light-harvesting chlorophyll a/bbinding protein is essential for the trimerization of light-harvesting chlorophyll a/b complex. Biochemistry 34(32):10224-10228.

Jansson S. 1999. A guide to the Lhc genes and their relatives in Arabidopsis. Trends in Plant Science 4(6):236-240 DOI 10.1016/S1360-1385(99)01419-3.

Klimmek F, Sjödin A, Noutsos C, Leister D, Jansson S. 2006. Abundantly and rarely expressed Lhc protein genes exhibit distinct regulation patterns in plants. Plant Physiology 140(3):793-804 DOI 10.1104/pp.105.073304.

Koziol AG, Borza T, Ishida K, Keeling P, Lee RW, Durnford DG. 2007. Tracing the evolution of the lightharvesting antennae in chlorophyll a/b-containing organisms. Plant Physiology 143(4):1802-1816 DOI 
447

448

449

450

451

452

453

454

455

456

457

458

459

460

461

462

463

464

465

466

467

468

469

470

471

472

473

474

475

476

477

478

479

480

481

482

10.1104/pp.106.092536.

Kumar A, Sharma S. 2008. An evaluation of a multipurpose oil seed crop for industrial uses (Jatropha curcas L): a review. Industrial Crops \& Products 28:1-10 DOI 10.1016/j.indcrop.2008.01.001.

Kumar S, Stecher G, Tamura K. 2016. MEGA7: Molecular Evolutionary Genetics Analysis version 7.0 for bigger datasets. Molecular Biology and Evolution 33(7):1870-1874 DOI 10.1093/molbev/msw054.

Kühlbrandt W, Wang DN, Fujiyoshi Y. 1994. Atomic model of plant light-harvesting complex by electron crystallography. Nature 367(6464):614-621 DOI 10.1038/367614a0.

Langmead B, Salzberg SL. 2012. Fast gapped-read alignment with Bowtie 2. Nature Methods 9(4):357-359 DOI 10.1038/nmeth.1923.

Li B, Dewey CN. 2011. RSEM: accurate transcript quantification from RNA-Seq data with or without a reference genome. BMC Bioinformatics 12:323 DOI 10.1186/1471-2105-12-323.

Li H, Tsuchimoto S, Harada K, Yamasaki M, Sakai H, Wada N, Alipour A, Sasai T, Tsunekawa A, Tsujimoto H, Ando T, Tomemori H, Sato S, Hirakawa H, Quintero VP, Zamarripa A, Santos P, Hegazy A, Ali AM, Fukui K. 2017. Genetic tracing of Jatropha curcas L. from its mesoamerican origin to the world. Frontiers in Plant Science 8:1539 DOI 10.3389/fpls.2017.01539.

Li XP, Gilmore AM, Caffarri S, Bassi R, Golan T, Kramer D, Niyogi KK. 2004. Regulation of photosynthetic light harvesting involves intrathylakoid lumen $\mathrm{pH}$ sensing by the PsbS protein. Journal of Biological Chemistry 279:22866-22874 DOI 10.1074/jbc.M402461200.

Li Y, Liu B, Zhang J, Kong F, Zhang L, Meng H, Li W, Rochaix JD, Li D, Peng L. 2019. OHP1, OHP2, and HCF244 form a transient functional complex with the photosystem II reaction center. Plant Physiology 179(1):195-208 DOI 10.1104/pp.18.01231.

Maghuly F, Laimer M. 2013. Jatropha curcas, a biofuel crop: functional genomics for understanding metabolic pathways and genetic improvement. Biotechnology Journal 8:1172-1182 DOI 10.1002/biot.201300231.

Mazumdar P, Singh P, Babu S, Siva R, Harikrishna JA. 2018. An update on biological advancement of Jatropha curcas L.: New insight and challenges. Renewable \& Sustainable Energy Reviews 91:903-917 DOI 10.1016/j.rser.2018.04.082.

Montané MH, Kloppstech K. 2000. The family of light-harvesting-related proteins (LHCs, ELIPs, HLIPs): was the harvesting of light their primary function? Gene 258(1-2):1-8 DOI 10.1016/S0378-1119(00)00413-3.

Montes JM, Melchinger AE. 2016. Domestication and breeding of Jatropha curcas L. Trends in Plant Science 21:1045-1057 DOI 10.1016/j.tplants.2016.08.008.

Mortazavi A, Williams BA, McCue K, Schaeffer L, Wold B. 2008. Mapping and quantifying mammalian transcriptomes by RNA-Seq. Nature Methods 5(7):621-628 DOI 10.1038/nmeth.1226.

Myouga F, Takahashi K, Tanaka R, Nagata N, Kiss AZ, Funk C, Nomura Y, Nakagami H, Jansson S, Shinozaki K. 2018. Stable accumulation of photosystem II requires ONE-HELIX PROTEIN1 (OHP1) of the light harvesting-like family. Plant Physiology 176(3):2277-2291 DOI 10.1104/pp.17.01782.

Ni J, Zhao ML, Chen MS, Pan BZ, Tao YB, Xu ZF. 2017. Comparative transcriptome analysis of axillary buds in

Peer) reviewing PDF | (2019:08:40457:4:0:NEW 6 Dec 2019) 
483

484

485

486

487

488

489

490

491

492

493

494

495

496

497

498

499

500

501

502

503

504

505

506

507

508

509

510

511

512

513

514

515

516

517

518

response to the shoot branching regulators gibberellin A3 and 6-benzyladenine in Jatropha curcas. Scientific Reports 7(1):11417 DOI 10.1038/s41598-017-11588-0.

Pan X, Li M, Wan T, Wang L, Jia C, Hou Z, Zhao X, Zhang J, Chang W. 2011. Structural insights into energy regulation of light-harvesting complex CP29 from spinach. Nature Structural \& Molecular Biology 18(3):309315 DOI 10.1038/nsmb.2008.

Rogl H, Kühlbrandt W. 1999. Mutant trimers of light-harvesting complex II exhibit altered pigment content and spectroscopic features. Biochemistry 38(49):16214-16222 DOI 10.1021/bi990739p.

Staneloni RJ, Rodriguez-Batiller MJ, Casal JJ. 2008. Abscisic acid, high-light, and oxidative stress downregulate a photosynthetic gene via a promoter motif not involved in phytochrome-mediated transcriptional regulation. Molecular Plant 1(1):75-83 DOI 10.1093/mp/ssm007.

Tibiletti T, Auroy P, Peltier G, Caffarri S. 2016. Chlamydomonas reinhardtii PsbS protein is functional and accumulates rapidly and transiently under high light. Plant Physiology 171(4):2717-2730 DOI 10.1104/pp.16.00572.

Tzvetkova-Chevolleau T, Franck F, Alawady AE, Dall'Osto L, Carrière F, Bassi R, Grimm B, Nussaume L, Havaux M. 2007. The light stress-induced protein ELIP2 is a regulator of chlorophyll synthesis in Arabidopsis thaliana. Plant Journal 50(5):795-809 DOI 10.1111/j.1365-313X.2007.03090.x.

Voorrips RE. 2002. MapChart: software for the graphical presentation of linkage maps and QTLs. Journal of Heredity 93:77-78.

Wang Y, Tan X, Paterson AH. 2013. Different patterns of gene structure divergence following gene duplication in Arabidopsis. BMC Genomics 14:652 DOI 10.1186/1471-2164-14-652.

Wu P, Zhou C, Cheng S, Wu Z, Lu W, Han J, Chen Y, Chen Y, Ni P, Wang Y, Xu X, Huang Y, Song C, Wang Z, Shi N, Zhang X, Fang X, Yang Q, Jiang H, Chen Y, Li M, Wang Y, Chen F, Wang J, Wu G. 2015. Integrated genome sequence and linkage map of physic nut (Jatropha curcas L.), a biodiesel plant. Plant Journal 81(5):810-821 DOI 10.1111/tpj.12761.

Zhang C, Zhang L, Zhang S, Zhu S, Wu P, Chen Y, Li M, Jiang H, Wu G. 2015. Global analysis of gene expression profiles in physic nut (Jatropha curcas L.) seedlings exposed to drought stress. BMC Plant Biology 15:17 DOI 10.1186/s12870-014-0397-x.

Zhang L, Zhang C, Wu P, Chen Y, Li M, Jiang H, Wu G. 2014. Global analysis of gene expression profiles in physic nut (Jatropha curcas L.) seedlings exposed to salt stress. PLoS One 9(5):e97878 DOI 10.1371/journal.pone.0097878.

Zou Z. 2018. Mining gene families in the castor bean genome. In: Rabinowicz P, Kole C (Eds.): The Castor Bean Genome, Springer, Switzerland, pp. 135-173.

Zou Z, Huang QX, An F. 2013. Genome-wide identification, classification and expression analysis of $L h c$ supergene family in castor bean (Ricinus communis L.). Agriculture Biotechnology 2:44-48, 51.

Zou Z, Huang QX, Xie GS, Yang LF. 2018. Genome-wide comparative analysis of papain-like cysteine protease family genes in castor bean and physic nut. Scientific Reports 8:331 DOI 10.1038/s41598-017-18760-6.

Peer] reviewing PDF | (2019:08:40457:4:0:NEW 6 Dec 2019) 
519

520

521

522

523

524

525

526

527

528

529

530

531

532

533

534

535

536

537

538

539

540

541

542

543

544

545

546

Zou Z, Yang JH. 2019a. Genomics analysis of the light-harvesting chlorophyll a/b-binding (Lhc) superfamily in cassava (Manihot esculenta Crantz). Gene 702:171-181 DOI 10.1016/j.gene.2019.03.071.

Zou Z, Yang JH. 2019b. Genome-wide comparison reveals divergence of cassava and rubber aquaporin family genes after the recent whole-genome duplication. BMC genomics 20:380 DOI 10.1186/s12864-019-5780-4.

Zou Z, Yang JH. 2019c. Genomic analysis of Dof transcription factors in Hevea brasiliensis, a rubber-producing tree. Industrial Crops \& Products 134:271-283 DOI 10.1016/j.indcrop.2019.04.013.

Zou Z, Yang JH, Zhang XC. 2019. Insights into genes encoding respiratory burst oxidase homologs (RBOHs) in rubber tree (Hevea brasiliensis Muell. Arg.). Industrial Crops \& Products 128:126-139 DOI 10.1016/j.indcrop.2018.11.005.

Zou Z, Yang LF, Gong J, Mo YY, Wang JK, Cao JH, An F, Xie GS. 2016. Genome-wide identification of Jatropha curcas aquaporin genes and the comparative analysis provides insights into the gene family expansion and evolution in Hevea brasiliensis. Frontiers in Plant Science 7:395 DOI 10.3389/fpls.2016.00395.

\section{Figure and Table legends}

Fig. 1 Chromosomal locations of $\boldsymbol{J} \boldsymbol{c L h} \boldsymbol{c}$ superfamily genes. Chromosome serial numbers are indicated at the top of each chromosome. (Chr: chromosome)

Fig. 2 Exon-intron structures of $\boldsymbol{J} \boldsymbol{c} \boldsymbol{L} \boldsymbol{h} \boldsymbol{c}$ superfamily genes. The graphic representation of the gene models is displayed using GSDS. (GSDS: gene structure display server)

Fig. 3 Phylogenetic and conserved motif analyses of jatropha, castor, cassava, and arabidopsis Lhc superfamily proteins. a. Phylogenetic analysis of Lhca, Lhcb, PsbS, ELIP, OHP, SEP, Psb33, and FCII subfamilies; b. Distribution of conserved motifs. Sequence alignment was performed using MUSCLE and unrooted phylogenetic trees were constructed using MEGA7 (maximum likelihood method; bootstrap, 1,000 replicates). Only bootstrap values at nodes supported by a posterior probability of $\geqslant 50 \%$ are given. The distance scale denotes the number of amino acid substitutions per site. The name of each OG is indicated next to the corresponding group. (OG: orthologous group)

Fig. 4 Tissue-specific expression profiles of JcLhc superfamily genes. Color scale represents FPKM normalized $\log _{10}$ transformed counts where navy indicates low expression and firebrick3 indicates high expression. (FPKM: fragments per kilobase of exon per million fragments mapped; IND: undifferentiated inflorescence of $0.5 \mathrm{~cm}$ diameter; PID1: female flower with carpel primordia beginning to differentiate; PID2: 
547 female flower with three distinct carpels formed; STD1: male flower with stamen primordia beginning to

548 differentiate; STD2: male flower with ten complete stamens formed)

549 Fig. 5 Expression profiles of JcLhc superfamily genes upon drought, salt, BA, or GA treatments. Color

550 scale represents RPKM normalized $\log _{10}$ transformed counts where navy indicates low expression and

551 firebrick3 indicates high expression. (RPKM: Reads per kilobase per million mapped reads)

552 Table 127 Lhc superfamily genes identified in jatropha. (AA: amino acid; At: Arabidopsis thaliana; bp:

553 base pair; CDS: coding sequence; EST: expressed sequence tag; Me: Manihot esculenta; OG: orthologous

554 group; Rc: Ricinus communis; TMH: transmembrane helix; TP: transit peptide)

555 Table 2 Detailed information of 25 motifs identified in this study. Motifs were identified using MEME. 
Figure 1

Fig. 1 Chromosomal locations of JcLhc superfamily genes.

Chromosome serial numbers are indicated at the top of each chromosome. (Chr: chromosome)

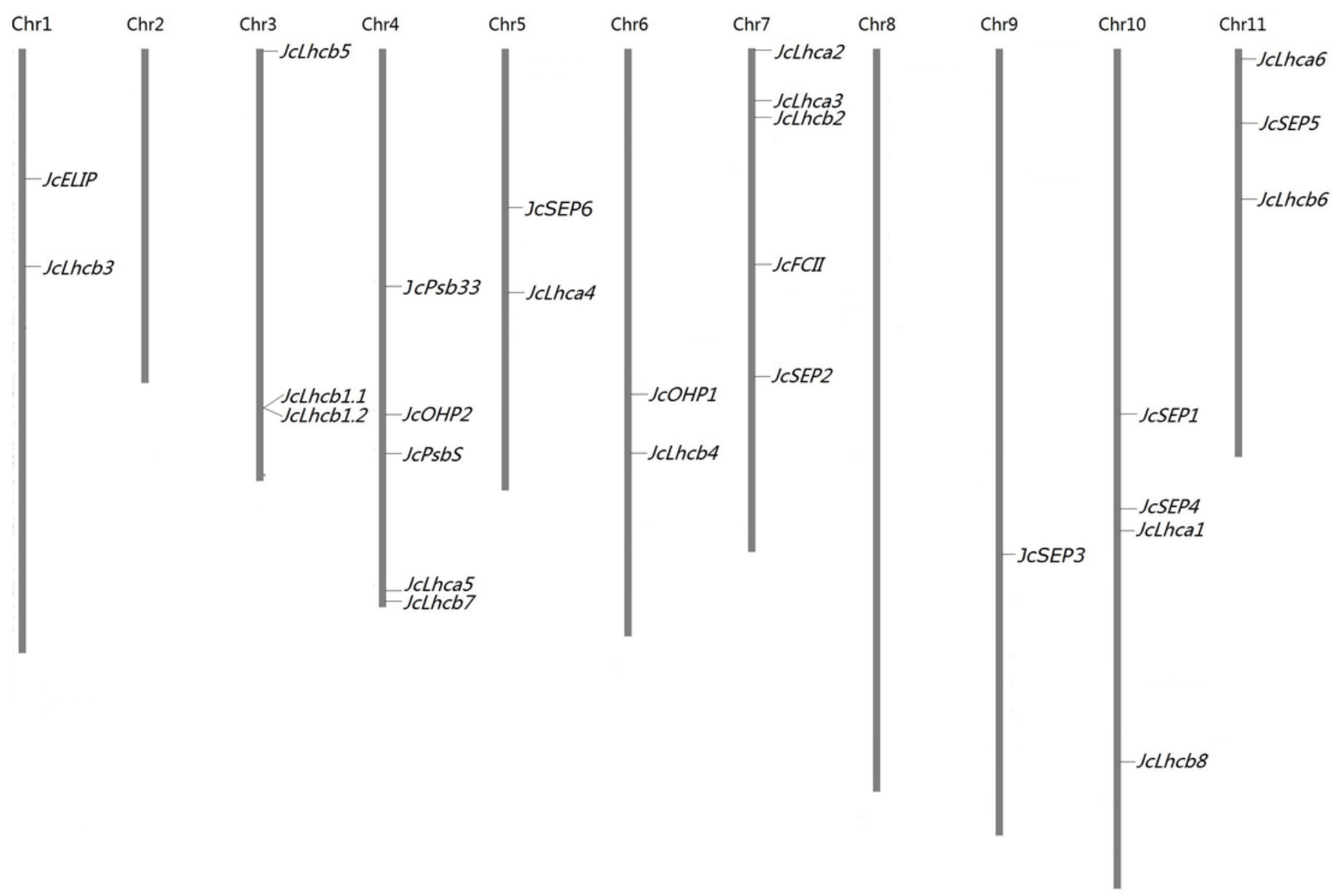


Figure 2

Fig. 2 Exon-intron structures of $J C L h c$ superfamily genes.

The graphic representation of the gene models is displayed using GSDS. (GSDS: gene structure display server)

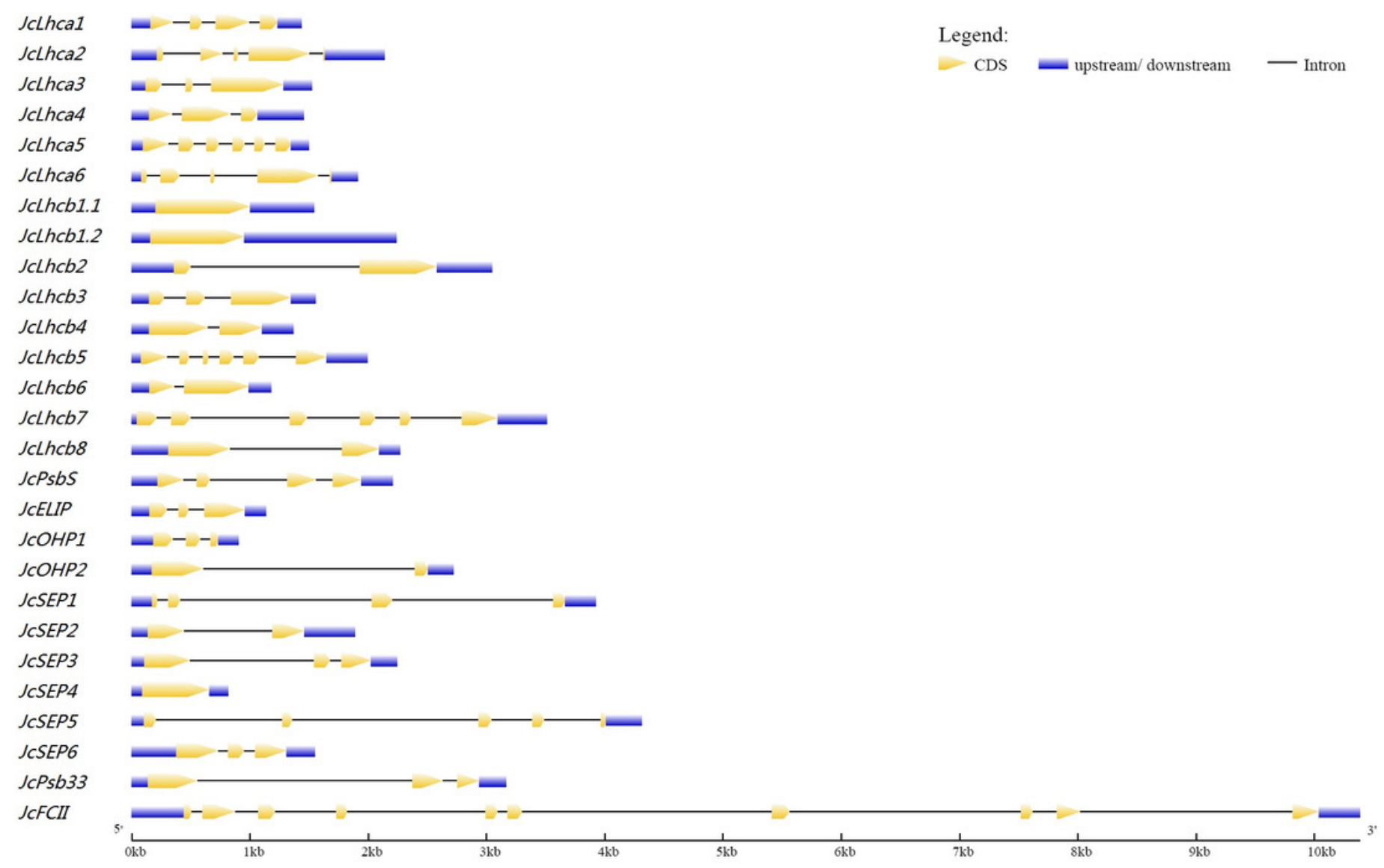




\section{Figure 3}

Fig. 3 Phylogenetic and conserved motif analyses of jatropha, castor, cassava, and arabidopsis Lhc superfamily proteins.

a. Phylogenetic analysis of Lhca, Lhcb, PsbS, ELIP, OHP, SEP, Psb33, and FCII subfamilies; $\mathbf{b}$. Distribution of conserved motifs. Sequence alignment was performed using MUSCLE and unrooted phylogenetic trees were constructed using MEGA7 (maximum likelihood method; bootstrap, 1,000 replicates). Only bootstrap values at nodes supported by a posterior probability of $\geq 50 \%$ are given. The distance scale denotes the number of amino acid substitutions per site. The name of each OG is indicated next to the corresponding group. (OG: orthologous group) 

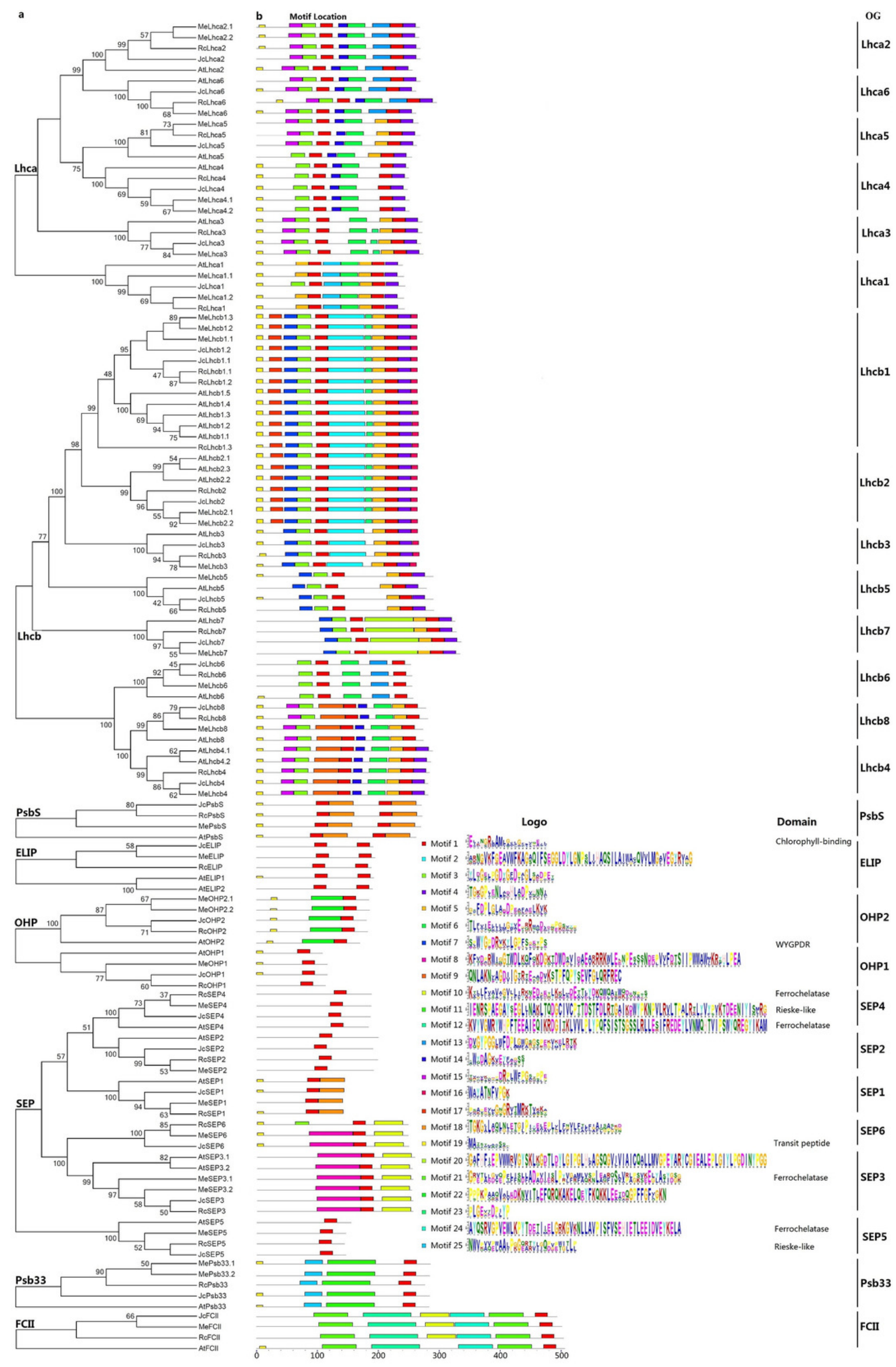

PeerJ reviewing PDF | (2019:08:40457:4:0:NEW 6 Dec 2019) 


\section{Figure 4}

Fig. 4 Tissue-specific expression profiles of $J c L h c$ superfamily genes.

Color scale represents FPKM normalized $\log _{10}$ transformed counts where navy indicates low expression and firebrick3 indicates high expression. (FPKM: fragments per kilobase of exon per million fragments mapped; IND: undifferentiated inflorescence of $0.5 \mathrm{~cm}$ diameter; PID1: female flower with carpel primordia beginning to differentiate; PID2: female flower with three distinct carpels formed; STD1: male flower with stamen primordia beginning to differentiate; STD2: male flower with ten complete stamens formed) 


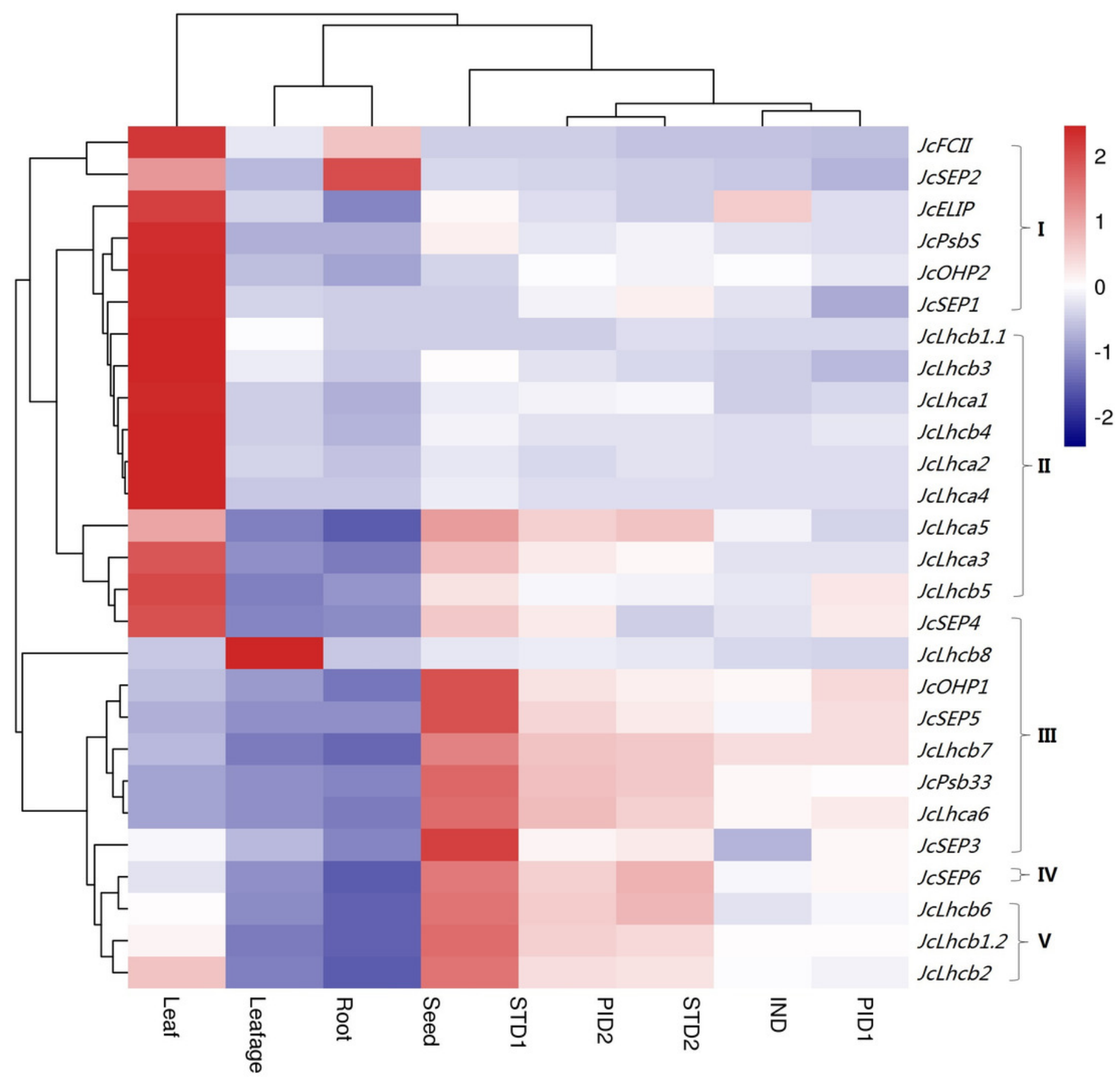




\section{Figure 5}

Fig. 5 Expression profiles of $J c L h c$ superfamily genes upon drought, salt, BA, or GA treatments.

Color scale represents RPKM normalized $\log _{10}$ transformed counts where navy indicates low expression and firebrick3 indicates high expression. (RPKM: Reads per kilobase per million mapped reads) 


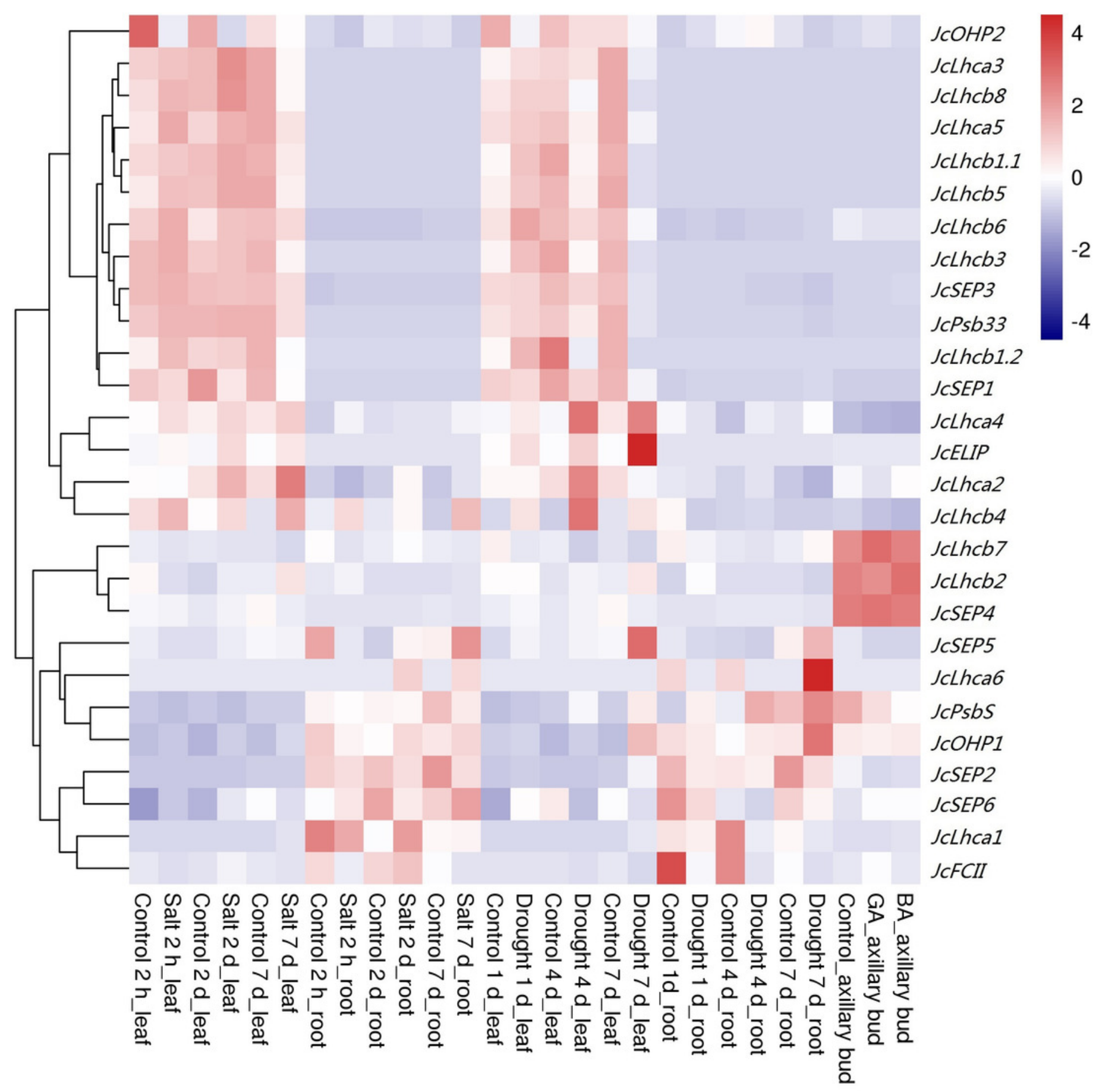




\section{Table $\mathbf{1}$ (on next page)}

Table 127 Lhc superfamily genes identified in jatropha.

(AA: amino acid; At: Arabidopsis thaliana; bp: base pair; CDS: coding sequence; EST: expressed sequence tag; Me: Manihot esculenta; OG: orthologous group; Rc: Ricinus communis; TMH: transmembrane helix; TP: transit peptide) 


\begin{tabular}{|c|c|c|c|c|c|c|c|c|c|c|c|c|c|c|}
\hline \multirow[t]{2}{*}{ Subfamily } & \multirow[t]{2}{*}{ Gene name } & \multirow[t]{2}{*}{ Locus ID } & \multirow[t]{2}{*}{ Scaffold position } & \multicolumn{2}{|c|}{$\begin{array}{l}\text { Nucleotide } \\
\text { length (bp, } \\
\text { from start to } \\
\text { stop codons) }\end{array}$} & \multirow[t]{2}{*}{$\begin{array}{c}\text { Intron } \\
\text { no. }\end{array}$} & \multirow[t]{2}{*}{$\begin{array}{c}\text { EST } \\
\text { no. }\end{array}$} & \multirow[t]{2}{*}{$\mathbf{A A}$} & \multirow[t]{2}{*}{$\begin{array}{c}\text { TP } \\
\text { length }\end{array}$} & \multirow[t]{2}{*}{ TMH } & \multicolumn{3}{|c|}{ Ortholog } & \multirow[t]{2}{*}{ OG } \\
\hline & & & & CDS & Gene & & & & & & Rc & $\mathrm{Me}$ & At & \\
\hline \multirow{6}{*}{ Lhca } & JcLhcal & JCGZ_23938 & scaffold794:74368-75803(-) & 738 & 1076 & 3 & 0 & 245 & 45 & 3 & RcLhcal & $\begin{array}{l}\text { MeLhca1.1 } \\
\text { MeLhca1.2 }\end{array}$ & AtLhca1 & Lhca1 \\
\hline & JcLhca2 & JCGZ_17961 & $\begin{array}{l}\text { scaffold502:3176588- } \\
3178724(+)\end{array}$ & 813 & 1491 & 4 & 1 & 270 & 58 & 3 & RcLhca2 & $\begin{array}{l}\text { MeLhca2.1 } \\
\text { MeLhca2.2 }\end{array}$ & AtLhca2 & Lhca2 \\
\hline & JcLhca 3 & JCGZ_15032 & scaffold42:178242-179765(-) & 816 & 1171 & 2 & 8 & 271 & 38 & 3 & RcLhca3 & MeLhca3 & AtLhca3 & Lhca3 \\
\hline & JcLhca4 & JCGZ_11643 & $\begin{array}{l}\text { scaffold328:2197266- } \\
2195814(-)\end{array}$ & 750 & 917 & 2 & 2 & 249 & 48 & 3 & RcLhca4 & $\begin{array}{l}\text { MeLhca4.1 } \\
\text { MeLhca4.2 }\end{array}$ & AtLhca4 & Lhca4 \\
\hline & JcLhca5 & JCGZ_04265 & scaffold159:84206-85704(+) & 795 & 1255 & 5 & 0 & 264 & 57 & 3 & RcLhca5 & MeLhca5 & AtLhca5 & Lhca5 \\
\hline & JcLhca6 & JCGZ_07509 & $\begin{array}{l}\text { scaffold211:3089530- } \\
3091440(-)\end{array}$ & 792 & 1612 & 4 & 0 & 263 & 42 & 3 & RcLhca6 & MeLhca6 & AtLhca6 & Lhca6 \\
\hline \multirow{9}{*}{ Lhcb } & JcLhcbl.I & JCGZ_04588 & scaffold160:101030-101541(+) & 798 & 798 & 0 & 28 & 265 & 35 & 3 & $\begin{array}{l}\text { RcLhcb1.1 } \\
\text { RcLhcb1.2 } \\
\text { RcLhcb1.3 }\end{array}$ & $\begin{array}{l}\text { MeLhcb1.1 } \\
\text { MeLhcb1.2 } \\
\text { MeLhcb1.3 }\end{array}$ & $\begin{array}{l}\text { AtLhcb1.1 } \\
\text { AtLhcb1.2 } \\
\text { AtLhcb1.3 } \\
\text { AtLhcb1.4 } \\
\text { AtLhcb1.5 }\end{array}$ & Lhcb1 \\
\hline & JcLhcbl.2 & JCGZ_04587 & scaffold160:97668-99902(-) & 798 & 798 & 0 & 17 & 265 & 35 & 3 & $\begin{array}{l}\text { RcLhcb1.1 } \\
\text { RcLhcb1.2 } \\
\text { RcLhcb1.3 }\end{array}$ & $\begin{array}{l}\text { MeLhcb1.1 } \\
\text { MeLhcb1.2 } \\
\text { MeLhcb1.3 }\end{array}$ & $\begin{array}{l}\text { AtLhcbl.1 } \\
\text { AtLhcbl.2 } \\
\text { AtLhcb1.3 } \\
\text { AtLhcb1.4 } \\
\text { AtLhcb1.5 }\end{array}$ & Lhcb1 \\
\hline & $J c L h c b 2$ & JCGZ_18481 & scaffold529:239615-242657(-) & 798 & 2225 & 1 & 10 & 265 & 37 & 3 & RcLhcb2 & $\begin{array}{l}\text { MeLhcb2.1 } \\
\text { MeLhcb2.2 }\end{array}$ & $\begin{array}{l}\text { AtLhcb2.1 } \\
\text { AtLhcb2.2 } \\
\text { AtLhcb2.3 }\end{array}$ & Lhcb2 \\
\hline & JcLhcb3 & JCGZ_00703 & scaffold108:360030-361580(-) & 804 & 1202 & 2 & 5 & 267 & 44 & 3 & RcLhcb3 & MeLhcb3 & AtLhcb3 & Lhcb3 \\
\hline & JcLhcb4 & JCGZ_25025 & scaffold843:295347-296708(+) & 858 & 957 & 1 & 8 & 285 & 31 & 3 & RcLhcb4 & MeLhcb4 & $\begin{array}{l}\text { AtLhcb4.1 } \\
\text { AtLhcb4.2 }\end{array}$ & Lhcb4 \\
\hline & $J c L h c b 8$ & JCGZ_01281 & scaffold1 1:738853-741122(+) & 840 & 1786 & 1 & 0 & 279 & 31 & 3 & RcLhcb8 & MeLhcb8 & AtLhcb8 & Lhcb8 \\
\hline & $J c L h c b 5$ & JCGZ_06701 & scaffold200:160436-162429(-) & 876 & 1573 & 5 & 1 & 291 & 41 & 3 & RcLhcb5 & MeLhcb5 & AtLhcb5 & Lhcb5 \\
\hline & JcLhcb6 & JCGZ_20203 & scaffold645:375633-376811(+) & 765 & 844 & 1 & 1 & 254 & 49 & 3 & RcLhcb6 & MeLhcb6 & AtLhcb6 & Lhcb6 \\
\hline & $J c L h c b 7$ & JCGZ_08016 & scaffold221:188978-192485(-) & 1014 & 3050 & 5 & 0 & 337 & 52 & 3 & RcLhcb7 & MeLhcb7 & AtLhcb7 & Lhcb7 \\
\hline PsbS & $J c P s b S$ & JCGZ_12094 & scaffold339:857142-859344(-) & 825 & 1726 & 3 & 2 & 274 & 62 & 4 & RcPsbS & MePsbS & AtPsbS & PsbS \\
\hline ELIP & $J c E L I P$ & JCGZ_02231 & $\begin{array}{l}\text { scaffold119:1376949- } \\
\text { 1378080(-) }\end{array}$ & 585 & 808 & 2 & 6 & 194 & 86 & 3 & RcELIP & MeELIP & $\begin{array}{l}\text { AtELIP1 } \\
\text { AtELIP2 }\end{array}$ & ELIP \\
\hline \multirow{2}{*}{ OHP } & JcOHPI & JCGZ_09105 & $\begin{array}{l}\text { scaffold250:2426033- } \\
2426931(-)\end{array}$ & 357 & 552 & 2 & 2 & 118 & 48 & 1 & RcOHP1 & MeOHP1 & AtOHP1 & OHP1 \\
\hline & JcOHP2 & JCGZ_08332 & scaffold224:432321-435041(+) & 552 & 2339 & 1 & 0 & 183 & 47 & 1 & $\mathrm{RcOHP} 2$ & $\begin{array}{l}\mathrm{MeOHP} 2.1 \\
\mathrm{MeOHP} 2.2\end{array}$ & AtOHP2 & OHP2 \\
\hline \multirow{6}{*}{ SEP } & JCSEPI & JCGZ_23193 & scaffold7:432788-436707(-) & 438 & 3498 & 3 & 3 & 145 & 71 & 2 & RcSEP1 & MeSEP1 & AtSEP1 & SEP1 \\
\hline & $J C S E P 2$ & JCGZ_09398 & scaffold255:592063-593949(+) & 582 & 1322 & 1 & 0 & 193 & 46 & 2 & RcSEP2 & MeSEP2 & AtSEP2 & SEP2 \\
\hline & JCSEP3 & JCGZ_03488 & scaffold137:779011-781250(+) & 780 & 1919 & 2 & 4 & 259 & 100 & 2 & RcSEP3 & $\begin{array}{l}\text { MeSEP3.1 } \\
\text { MeSEP3.2 }\end{array}$ & $\begin{array}{l}\text { AtSEP3.1 } \\
\text { AtSEP3.2 }\end{array}$ & SEP3 \\
\hline & JCSEP6 & JCGZ_26324 & $\begin{array}{l}\text { scaffold906:2486216- } \\
2487759(-)\end{array}$ & 759 & 932 & 2 & 0 & 252 & 88 & 2 & RcSEP6 & MeSEP6 & - & SEP6 \\
\hline & JCSEP4 & JCGZ_06634 & scaffold20:991705-992601(+) & 570 & 570 & 0 & 0 & 189 & 56 & 2 & RcSEP4 & MeSEP4 & AtSEP4 & SEP4 \\
\hline & JCSEP5 & JCGZ_07816 & $\begin{array}{l}\text { scaffold211:5206555- } \\
5210867(-)\end{array}$ & 447 & 3909 & 4 & 0 & 148 & 75 & 1 & RcSEP5 & MeSEP5 & AtSEP5 & SEP5 \\
\hline Psb33 & $J c P s b 33$ & JCGZ_17235 & scaffold5:830004-833169(+) & 867 & 2803 & 2 & 1 & 288 & 62 & 1 & RcPsb33 & $\begin{array}{l}\text { MePsb33.1 } \\
\text { MePsb33.2 }\end{array}$ & AtPsb33 & Psb33 \\
\hline FCII & $J_{C F C I I}$ & JCGZ_24260 & scaffold813:61000-71385(-) & 1500 & 9600 & 9 & 0 & 499 & 86 & 1 & RcFCII & MeFCII & AtFCII & FCII \\
\hline
\end{tabular}




\section{Table 2 (on next page)}

Table 2 Detailed information of 25 motifs identified in this study.

Motifs were identified using MEME. 


\begin{tabular}{|c|c|c|c|c|}
\hline Motif & E-value & Sites & Width & Best match \\
\hline Motif 1 & $2.5 \mathrm{e}-1988$ & 205 & 21 & EJINGRLAMLGFLGFLVQEIL \\
\hline Motif 2 & $6.2 \mathrm{e}-1170$ & 24 & 60 & ARNGVKFGEAVWFKAGAQIFSEGGLDYLGNPSLIHAQSILAIWACQVVLMGAVEGYRVAG \\
\hline Motif 3 & 9.4e-992 & 69 & 23 & YLDGELPGDYGFDPAGLSADPET \\
\hline Motif 4 & 8.6e-894 & 64 & 21 & TGKGPJENLADHLADPVHNNI \\
\hline Motif 5 & 2.6e-582 & 58 & 21 & GSFDPLGLADDPEAFAELKVK \\
\hline Motif 6 & $3.0 \mathrm{e}-546$ & 40 & 29 & TLFVIELJLIGYVEFRRWADLDNPGSVYP \\
\hline Motif 7 & $1.9 \mathrm{e}-374$ & 32 & 21 & SPWYGPDRVKYLGPFSGETPS \\
\hline Motif 8 & $4.2 \mathrm{e}-331$ & 8 & 73 & KFVDPRWIGGTWDLKQFZKDGKTDWDAVIDAEAKRRKWLEENPESSSNDEPVVFDTSIIPWWAWIKRYHLPEA \\
\hline Motif 9 & $1.4 \mathrm{E}-216$ & 9 & 41 & QNLAKNVAGDIIGTRTEAADVKSTPFQPYSEVFGLQRFREC \\
\hline Motif 10 & $3.5 \mathrm{E}-205$ & 12 & 48 & KTLLFVAVAGVLLIRKNEDIETLKKLLDETTLYDKQWQATWKDZNPSS \\
\hline Motif 11 & $9 \mathrm{E}-200$ & 5 & 80 & IENRSPAEGAYSEGLJNAKLTQDGCIVCPTTDSTFDLRTGAIKDWYPKNPVLRVLTPALRTLYVYPVKTDEENIYISLRG \\
\hline Motif 12 & $1 \mathrm{E}-170$ & 4 & 80 & KVYVGMRYWHPFTEEAIEQIKRDGITKLVVLPLYPQFSISTSGSSLRLLESIFREDEYLVNMQHTVIPSWYQREGYIKAM \\
\hline Motif 13 & $8.1 \mathrm{E}-166$ & 13 & 29 & DVGYPGGLWFDPLGWGSGSPEKVKELRTK \\
\hline Motif 14 & $3.6 \mathrm{E}-159$ & 27 & 15 & SWYDAGKVEYFAGSS \\
\hline Motif 15 & $1.8 \mathrm{E}-154$ & 25 & 21 & TVCVKADPDRPLWFPGSTPPE \\
\hline Motif 16 & $5.4 \mathrm{E}-153$ & 24 & 11 & WAYATNFVPGK \\
\hline Motif 17 & 7.6E-149 & 20 & 21 & PSAPEVMGNGRVTMRKTVKKA \\
\hline Motif 18 & $8.6 \mathrm{E}-142$ & 12 & 41 & TGKGLLAQLNJETGJPIYELEPLVLFNVLFALFAAINASKD \\
\hline Motif 19 & $3.6 \mathrm{E}-140$ & 80 & 11 & MATSTLAASSS \\
\hline Motif 20 & $6.1 \mathrm{E}-140$ & 4 & 80 & GAFHFIEPVWWRVGYSKLKGDTLDYLGIPGLHLAGSQGVIVIAICQALLMVGPEYARYCGIEALEPLGIYLPGDINYPGG \\
\hline Motif 21 & $3.4 \mathrm{E}-142$ & 8 & 57 & GPEPLLGVZPFLINLLADPVIERLPYVGAFLVKPLEAFISLVPLPKVEEGLASYGGG \\
\hline Motif 22 & $2 \mathrm{E}-98$ & 5 & 53 & PPPKPAAQVALDDKNVITLEFQRQKAKELQEYFKQKKLEETDQGPFFGFLGKN \\
\hline Motif 23 & 4.3E-98 & 23 & 11 & PLGEVTDPJYP \\
\hline Motif 24 & 4.6E-92 & 4 & 57 & AYQSRVGPVEWLKPYTDETIIELGRKGVKNLLAVPISFVSEHIETLEEIDVEYKELA \\
\hline Motif 25 & $1.4 \mathrm{E}-106$ & 10 & 29 & NWVPAVPLAALPGGZATYJGQPVPTGLLP \\
\hline
\end{tabular}

1 